\title{
Machado Joseph disease maps to the same region of chromosome 14 as the spinocerebellar ataxia type 3 locus
}

\author{
Elspeth C Twist, Leanne K Casaubon, Martin H Ruttledge, Valluri S Rao, Patrick M \\ Macleod, Joao Radvany, Zuyun Zhao, Roger N Rosenberg, Lindsay A Farrer, Guy A \\ Rouleau
}

Centre for Research in Neuroscience, McGill University and the Montreal General Hospital Research Institute, 1650 Cedar Avenue, Montreal, Quebec H3G 1A4, Canada

E C Twist

L K Casaubon

M H Ruttledge

G A Rouleau

Department of

Neurology, Boston

University School of

Medicine, 80 East

Concord Street,

Boston, USA

V S Rao

L A Farrer

Section of Genetics, Department of

Laboratory Medicine,

Victoria General

Hospital, Victoria,

British Columbia

V8Z 6R5, Canada

P M Macleod

Neurologia Hospital Israelita Albert

Einstein, Sao Paulo,

Brazil

J Radvany

Department of Human Genetics, University of Utah, Salt Lake City,

Utah 84112, USA

Z Zhao

Department of

Neurology, University

of Texas South

of Texas South

Western Medical

USA

R N Rosenberg

School of Public

Health, Boston

University School of

Medicine and the

Department of

Neurology, Harvard

University School of

University School of

Medicin

L A Farrer

Correspondence to:

Dr Twist.

Received 24 June 1994

Revised version accepted fo publication 15 August 1994

\begin{abstract}
Machado Joseph disease (MJD) is an autosomal dominantly inherited neurodegenerative disorder primarily affecting the motor system. It can be divided into three phenotypes based on the variable combination of a range of clinical symptoms including pyramidal and extrapyramidal features, cerebellar deficits, and distal muscle atrophy. MJD is thought to be caused by mutation of a single gene which has recently been mapped, using genetic linkage analysis, to a $29 \mathrm{cM}$ region on chromosome 14q24.3-q32 in five Japanese families. A second disorder, spinocerebellar ataxia type 3 (SCA3), which has clinical symptoms similar to MJD, has also been linked to the same region of chromosome 14q in two French families. In order to narrow down the region of chromosome 14 which contains the MJD locus and to determine if this region overlaps with the predisposing locus for SCA3, we have performed genetic linkage analysis in seven MJD families, six of Portuguese/Azorean origin and one of Brazilian origin, using nine microsatellite markers mapped to 14q24.3-q32. Our results localise the MJD locus in these families to an $11 \mathrm{cM}$ interval flanked by the markers D14S68 and AFM343vf1. In addition we show that this $11 \mathrm{cM}$ interval maps within the $15 \mathrm{cM}$ interval containing the SCA3 locus, suggesting that these diseases are allelic.
\end{abstract}

\section{( $(\mathcal{H}$ Med Genet 1995;32:25-31)}

Machado Joseph disease (MJD) is an inherited neurodegenerative disorder which primarily affects the motor system. ${ }^{1}$ It shows an autosomal dominant pattern of transmission and a mean age of onset of $37 \cdot 4$ years (SD 14.1). Pathologically, there is neuronal loss in the dentate nucleus of the cerebellum as well as progressive loss of neurones and gliosis in the substantia nigra and basis pontis. In addition, there is significant motor neurone loss in the anterior horn of the spinal cord and in motor cranial nerve nuclei. ${ }^{2-7}$ The spinal cord also shows demyelination and there is atrophy of the spinocerebellar tracts. These morphological changes give rise to a wide range of clinical symptoms including cerebellar ataxia, pro- gressive external ophthalmoplegia, pyramidal signs, dystonia, rigidity, amyotrophy, and peripheral neuropathy. ${ }^{3589}$

Based on the variable combination of these clinical symptoms in different persons, MJD can be divided into three phenotypes: type I begins in the second or third decade with pyramidal and extrapyramidal features and has a rapid clinical course; type II occurs most frequently in the second to fourth decade with predominantly cerebellar deficits; and type III begins in the fifth to seventh decade with distal muscle atrophy being the prominant feature. ${ }^{9}$ The reasons for such variation in clinical presentation remain to be established but genetic heterogeneity seems unlikely since different subtypes are frequently seen within the same family. ${ }^{910}$ In addition, the phenotype is not fixed but can change over time. ${ }^{59}$ Thus, it appears that MJD is the result of a single gene mutation which results in variable expression of the disease. ${ }^{10}$

MJD was initially described in three American families of Portuguese/Azorean descent. ${ }^{2812}$ The disease is most prevalent (1: 4000) in the Portuguese islands of the Azores, as well as in Portuguese Americans from New England and California. It is now generally accepted, however, that the disease also exists in other ethnic groups, for example, Japanese, ${ }^{71-17}$ Aboriginal Australians, ${ }^{18}$ black Americans, ${ }^{1920}$ and Italian, ${ }^{2122}$ Spanish, Russian, and Chinese kindreds from the USA as well as Spanish and Chinese kindreds from mainland Spain and China. ${ }^{23}$ It is possible that these populations have links with Portugal or, alternatively, MJD may have arisen in these groups as a result of different ancestral mutations of the MJD gene.

The gene for MJD has recently been mapped to a $29 \mathrm{cM}$ interval on chromosome $14 \mathrm{q} 24.3-$ q32 in five Japanese kindreds. ${ }^{14}$ Subsequently, a second disorder, spinocerebellar ataxia type 3 (SCA3), has been mapped to the same region of chromosome 14q in two French families. ${ }^{24}$ In order to narrow down the region of chromosome 14 which contains the MJD locus and to determine if this region overlaps with the predisposing locus for SCA3, we have performed genetic linkage analysis in seven families segregating MJD, six Portuguese/Azorean families, and one Brazilian family, using nine microsatellite markers mapped to 14q24.3q32. Our results show that the MJD locus is localised to an $11 \mathrm{cM}$ interval flanked by the 
Table 1 Machado foseph families used for linkage analysis

\begin{tabular}{lclc}
\hline Pedigree identification & $\begin{array}{l}\text { No of persons } \\
\text { sampled }\end{array}$ & $\begin{array}{l}\text { No of persons } \\
\text { affected }\end{array}$ & $\begin{array}{l}\text { No of persons } \\
\text { at risk }\end{array}$ \\
\hline MJD-1 & 19 & 11 & 5 \\
MJD-2 & 18 & 10 & 5 \\
MJD-3A & 9 & 3 & 4 \\
MJD-3B & 22 & 12 & 6 \\
MJD-4 & 11 & 3 & 5 \\
MJD-11 & 13 & 5 & 6 \\
MJD-B1 & 101 & 32 & 56 \\
Total & 193 & 76 & 87 \\
\hline
\end{tabular}

markers D14S68 and AFM343vf1. In addition we show that this $11 \mathrm{cM}$ interval lies within the $15 \mathrm{cM}$ interval containing the SCA 3 locus, indicating that these diseases may be allelic.

\section{Materials and methods}

Seven pedigrees of known Portuguese/Azorean descent which were segregating MJD were selected for linkage analysis: five from New England (identified as MJD-1, MJD-2, MJD-3A, MJD-3B, and MJD-4), one from California (identified as MJD-11), and one from Santa Catarina, Brazil (identified as MJD-B1). All seven pedigrees have been described previously. ${ }^{25-27}$ Blood was collected from 193 persons, 76 of whom are affected and 87 of whom are at risk (table 1). DNA was extracted as previously described ${ }^{28}$ and, in addition, lymphoblastoid cell lines were established by Epstein Barr virus transformation. ${ }^{28}$

Linkage analysis was carried out using a range of highly informative di- and tetranucleotide repeat polymorphic markers (fig 1). Polymerase chain reaction (PCR) amplification of the desired fragments was carried out as described previously. ${ }^{29}$ PCR reactions were subjected to a hot start of $94^{\circ} \mathrm{C}$ for two

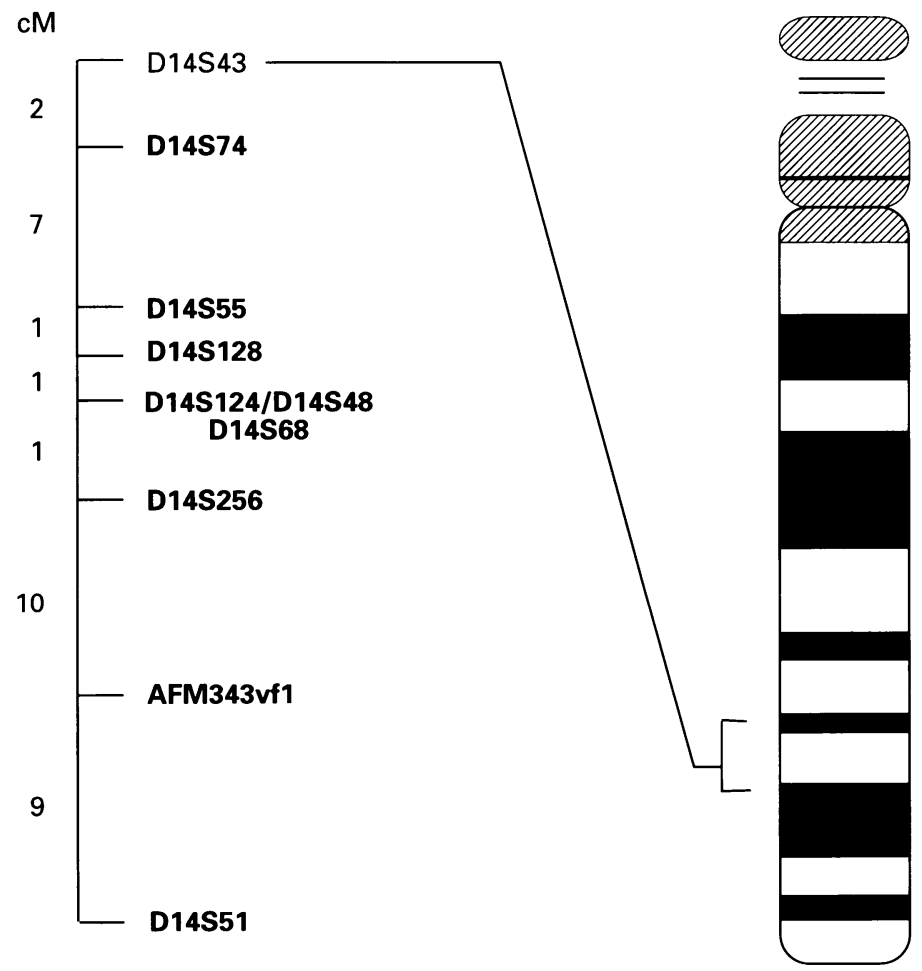

13 12

11.1

11.2

12

13

Figure 1 Linkage map of markers on chromosome $14 q$ in the region of the MFD locus. Markers used in this study are highlighted in bold print. minutes followed by 30 cycles of denaturing for one second at $94^{\circ} \mathrm{C}$ and then one minute at $92^{\circ} \mathrm{C}$, annealing for 45 seconds at temperatures ranging from $52^{\circ} \mathrm{C}$ to $57^{\circ} \mathrm{C}$ depending on the primer pairs, and elongation for one minute at $72^{\circ} \mathrm{C}$ followed by a final extension of five minutes at $72^{\circ} \mathrm{C}$ and then cooling of the product to $4^{\circ} \mathrm{C}$. DNA fragments were resolved on $5 \%$ or $6 \%$ polyacrylamide denaturing sequence gels for varying lengths of time depending on the size of the DNA fragment. Gels were dried and exposed to $x$ ray film for three days.

Linkage between the MJD locus and the chromosome 14 markers was analysed by the computer program LIPED $^{30}$ using an age at onset correction function ${ }^{31}$ which assumed a normal distribution with a mean of $37 \cdot 4$ (SD $14 \cdot 1),{ }^{9}$ autosomal dominant transmission of $\mathrm{MJD}$, and mutant allele frequency of 0.0005 . Allele frequencies for the markers were calculated from genotype analysis of a sample of 30 spouses of family members.

The genetic map of chromosome 14 used to position the MJD locus (fig 1) was based on the Généthon map ${ }^{32}$ and the map according to Takiyama et al. ${ }^{14}$ Two additional markers, D14S124 and D14S128, were inserted into the map by multilocus linkage analysis. $\mathrm{CEPH}$ reference pedigree data were obtained from the Utah and Collaborative Human Linkage Center data bases. Odds for marker order and distances were estimated using the CRIMAP program. ${ }^{33}$ The marker order D14S74D14S55-D14S128-D14S124-D14S48-D14S51 was equally likely as the order D14S74D14S55-D14S128-D14S48-D14S124-D14S51. However, haplotype analysis in the MJD families favoured the former order. This marker order was 1000:1 times more likely than any other possible order. ${ }^{33}$ D14S68 was positioned according to Stevanin et al. ${ }^{24}$

Evaluation of the support for linkage of MJD within each interval on the genetic map (fig 1) was carried out by multilocus linkage analysis using the LINKMAP program (version 4.9) from the LINKAGE package. ${ }^{34}$ In these analyses, age dependent penetrance of MJD was defined as a step function based on 15 age intervals corresponding as closely as possible to the function used in the LIPED analyses. D14S48 and D14S124 were treated as a haplotype since recombination has not been observed between them. Computer analyses were facilitated by reducing the observed alleles for each marker to four using the scheme of Braverman $^{35}$ which is an implementation of a method proposed by Ott. ${ }^{36}$ Allele reductions were done by hand. A series of overlapping four loci (MJD plus three marker loci) were carried out in a manner previously described, ${ }^{37}$ which allowed comparison of results over all intervals and efficient computation. Because an age correction function may not adequately account for non-penetrance in some persons, analyses were repeated after changing the disease penetrance in all at risk persons to zero (that is, a zero penetrance model). This latter model is similar to an "affecteds only" model in that normal offspring contribute no linkage information with regard to MJD; however, they 
Table 2 Pairwise lod scores between chromosome 14 markers and the Machado foseph disease locus for individual families

\begin{tabular}{|c|c|c|c|c|c|c|c|c|}
\hline & $\Theta$ & & & & & & & \\
\hline & 0.00 & 0.01 & 0.05 & $0 \cdot 10$ & 0.20 & 0.40 & $Z \max$ & $(\Theta)$ \\
\hline $\begin{array}{l}\text { D14S48 } \\
\text { MJD-B1 } \\
\text { MJD-1 } \\
\text { MJD-2 } \\
\text { MJD-3A } \\
\text { MJD-3B } \\
\text { MJD-4 } \\
\text { MJD-11 } \\
\text { Total }\end{array}$ & $\begin{array}{r}2.82 \\
-1.03 \\
1.21 \\
0.63 \\
-\propto \\
0.04 \\
0.87 \\
-x\end{array}$ & $\begin{array}{r}3.80 \\
-0.53 \\
1.20 \\
0.62 \\
-1.12 \\
0.05 \\
0.86 \\
3.88\end{array}$ & $\begin{array}{r}4.06 \\
0.01 \\
1 \cdot 15 \\
0.58 \\
-0.50 \\
0.06 \\
0.81 \\
6.17\end{array}$ & $\begin{array}{r}3 \cdot 82 \\
0 \cdot 24 \\
1.05 \\
0.53 \\
-0 \cdot 26 \\
0.07 \\
0 \cdot 72 \\
6 \cdot 17\end{array}$ & $\begin{array}{r}3.00 \\
0.39 \\
0.78 \\
0 \cdot 41 \\
-0.08 \\
0.05 \\
0.51 \\
5.06\end{array}$ & $\begin{array}{r}0.98 \\
0 \cdot 23 \\
0 \cdot 19 \\
0 \cdot 16 \\
-0 \cdot 01 \\
0 \cdot 00 \\
0 \cdot 07 \\
1 \cdot 62\end{array}$ & $6 \cdot 25$ & 0.07 \\
\hline $\begin{array}{c}\text { D14S51 } \\
\quad \text { MJD-B1 } \\
\text { MJD-1 } \\
\text { MJD-2 } \\
\text { MJD-3B } \\
\text { MJD-4 } \\
\text { MJD-11 } \\
\text { Total }\end{array}$ & $\begin{array}{r}4.49 \\
-x \\
-x \\
-x \\
-0.05 \\
0.89 \\
-\propto\end{array}$ & $\begin{array}{r}4.40 \\
-0.73 \\
-1.78 \\
-3.85 \\
0.00 \\
0.87 \\
-1.09\end{array}$ & $\begin{array}{r}4.05 \\
0 \cdot 11 \\
-0.83 \\
-1.94 \\
0.12 \\
0.81 \\
2.32\end{array}$ & $\begin{array}{r}3.56 \\
0.45 \\
-0.42 \\
-1.07 \\
0.17 \\
0.72 \\
3.41\end{array}$ & $\begin{array}{r}2.53 \\
0.59 \\
-0.11 \\
-0.32 \\
0.17 \\
0.52 \\
3.38\end{array}$ & $\begin{array}{l}0.61 \\
0.20 \\
0.00 \\
0.03 \\
0.00 \\
0.11 \\
0.95\end{array}$ & 3.41 & $0 \cdot 10$ \\
\hline \begin{tabular}{l} 
D14S55 \\
\multicolumn{1}{l}{ MJD-B1 } \\
MJD-1 \\
MJD-2 \\
MJD-3B \\
MJD-4 \\
MJD-11 \\
Total
\end{tabular} & $\begin{array}{r}-x \\
-x \\
-0.46 \\
-x \\
-0.73 \\
-0.28 \\
-\infty\end{array}$ & $\begin{array}{r}0.42 \\
-3.99 \\
-0.43 \\
-2.48 \\
-0.67 \\
-0.27 \\
-7.42\end{array}$ & $\begin{array}{r}1.35 \\
-2.38 \\
-0.30 \\
-1.29 \\
-0.49 \\
-0.26 \\
-3.37\end{array}$ & $\begin{array}{r}1.62 \\
-1.42 \\
-0.19 \\
-0.73 \\
-0.36 \\
-0.22 \\
-1.30\end{array}$ & $\begin{array}{r}1.51 \\
-0.58 \\
-0.07 \\
0.23 \\
-0.21 \\
-0.14 \\
0.74\end{array}$ & $\begin{array}{r}0.29 \\
-0.05 \\
0.00 \\
0.05 \\
-0.05 \\
-0.02 \\
0.22\end{array}$ & 3.41 & $0 \cdot 20$ \\
\hline $\begin{array}{l}\text { D14S74 } \\
\text { MJD-B1 } \\
\text { MJD-1 } \\
\text { MJD-2 } \\
\text { MJD-3A } \\
\text { MJD-3B } \\
\text { MJD-4 } \\
\text { MJD-11 } \\
\text { Total }\end{array}$ & $\begin{array}{r}-x \\
-x \\
2 \cdot 07 \\
0 \cdot 63 \\
-1 \cdot 11 \\
-x \\
-x \\
-x\end{array}$ & $\begin{array}{r}1.10 \\
-0.59 \\
2.01 \\
0.62 \\
-1.05 \\
-1.29 \\
-3.17 \\
-2.39\end{array}$ & $\begin{array}{r}2.05 \\
0.02 \\
1.83 \\
0.58 \\
-0.33 \\
-0.63 \\
-1.85 \\
1.67\end{array}$ & $\begin{array}{r}2.12 \\
0.20 \\
1.61 \\
0.53 \\
0.13 \\
-0.37 \\
-1.17 \\
3.05\end{array}$ & $\begin{array}{r}1.68 \\
0.26 \\
1.10 \\
0.41 \\
0.36 \\
-0.14 \\
-0.46 \\
3.21\end{array}$ & $\begin{array}{r}0.39 \\
0.10 \\
0.15 \\
0.16 \\
0.07 \\
-0.01 \\
-0.03 \\
0.83\end{array}$ & 3.35 & $0 \cdot 18$ \\
\hline $\begin{array}{l}\text { D14S124 } \\
\text { MJD-B1 } \\
\text { MJD-1 } \\
\text { MJD-2 } \\
\text { MJD-3B } \\
\text { MJD-4 } \\
\text { MJD-11 } \\
\text { Total }\end{array}$ & $\begin{array}{r}-0.23 \\
-0.97 \\
1.69 \\
0.73 \\
-0.19 \\
1.82 \\
2.84\end{array}$ & $\begin{array}{r}0.89 \\
0.07 \\
1.65 \\
0.71 \\
-0.14 \\
1.78 \\
4.96\end{array}$ & $\begin{array}{r}1.27 \\
0.67 \\
1.53 \\
0.64 \\
-0.02 \\
1.63 \\
5.71\end{array}$ & $\begin{array}{l}1 \cdot 19 \\
0.83 \\
1.36 \\
0.55 \\
0.06 \\
1.43 \\
5.42\end{array}$ & $\begin{array}{l}0.76 \\
0.77 \\
1.00 \\
0.36 \\
0.11 \\
1.01 \\
4 \cdot 01\end{array}$ & $\begin{array}{l}0 \cdot 12 \\
0.28 \\
0 \cdot 23 \\
0.04 \\
0.04 \\
0 \cdot 16 \\
0.87\end{array}$ & $5 \cdot 71$ & 0.05 \\
\hline $\begin{array}{l}\text { D14S128 } \\
\text { MJD-B1 } \\
\text { MJD-1 } \\
\text { MJD-2 } \\
\text { MJD-3A } \\
\text { MJD-3B } \\
\text { MJD-4 } \\
\text { MJD-11 } \\
\text { Total }\end{array}$ & $\begin{array}{r}-x \\
-0.70 \\
2.88 \\
0.63 \\
-x \\
-x \\
2.32 \\
-x\end{array}$ & $\begin{array}{r}1.79 \\
0.44 \\
2 \cdot 83 \\
0.62 \\
-1 \cdot 12 \\
-0.82 \\
2.27 \\
6.01\end{array}$ & $\begin{array}{r}3.28 \\
1.03 \\
2.61 \\
0.58 \\
-0.51 \\
-0.20 \\
2.07 \\
8.86\end{array}$ & $\begin{array}{r}3.46 \\
1.17 \\
2.34 \\
0.53 \\
-0.28 \\
0.01 \\
1.82 \\
9.05\end{array}$ & $\begin{array}{r}2.84 \\
1.03 \\
1.74 \\
0.41 \\
-0.12 \\
0.13 \\
1.29 \\
7 \cdot 32\end{array}$ & $\begin{array}{r}0.68 \\
0.31 \\
0.39 \\
0.16 \\
-0.03 \\
0.06 \\
0.21 \\
1.78\end{array}$ & $9 \cdot 13$ & 0.08 \\
\hline $\begin{array}{l}\text { D14S256 } \\
\text { MJD-B1 } \\
\text { MJD-1 } \\
\text { MJD-2 } \\
\text { MJD-3A } \\
\text { MJD-3B } \\
\text { MJD-4 } \\
\text { MJD-11 } \\
\text { Total }\end{array}$ & $\begin{array}{l}8.32 \\
2.06 \\
1.06 \\
0.63 \\
-x \\
0.64 \\
0.30 \\
-\propto\end{array}$ & $\begin{array}{r}8 \cdot 16 \\
2.04 \\
1.04 \\
0.62 \\
-1 \cdot 79 \\
0.61 \\
0.29 \\
10.94\end{array}$ & $\begin{array}{r}7.50 \\
1.95 \\
0.94 \\
0.58 \\
-0.94 \\
0.53 \\
0.26 \\
10.82\end{array}$ & $\begin{array}{r}6.66 \\
1.80 \\
0.81 \\
0.53 \\
-0.52 \\
0.43 \\
0.21 \\
9.92\end{array}$ & $\begin{array}{r}4 \cdot 89 \\
1.38 \\
0.56 \\
0 \cdot 41 \\
-0 \cdot 16 \\
0 \cdot 25 \\
0 \cdot 12 \\
7 \cdot 45\end{array}$ & $\begin{array}{l}1.29 \\
0.38 \\
0.09 \\
0.16 \\
0.00 \\
0.04 \\
0.02 \\
1.98\end{array}$ & 11.07 & 0.02 \\
\hline $\begin{array}{l}A F M 343 v f 1 \\
\text { MJD-B1 } \\
\text { MJD-1 } \\
\text { MJD-2 } \\
\text { MJD-3B } \\
\text { MJD-4 } \\
\text { MJD-11 } \\
\text { Total }\end{array}$ & $\begin{array}{l}3.58 \\
1.70 \\
2.88 \\
-\propto \\
0.45 \\
0.99 \\
-\propto\end{array}$ & $\begin{array}{r}5.09 \\
1.68 \\
2.83 \\
-1.67 \\
0.43 \\
1.04 \\
9.40\end{array}$ & $\begin{array}{r}5.22 \\
1.59 \\
2.61 \\
-0.46 \\
0.37 \\
1.12 \\
10.45\end{array}$ & $\begin{array}{r}4.80 \\
1.43 \\
2.34 \\
-0.01 \\
0.30 \\
1.10 \\
9.96\end{array}$ & $\begin{array}{l}3.61 \\
1.05 \\
1.74 \\
0.25 \\
0.18 \\
0.87 \\
7.70\end{array}$ & $\begin{array}{l}0.96 \\
0 \cdot 20 \\
0 \cdot 38 \\
0 \cdot 10 \\
0.02 \\
0 \cdot 17 \\
1 \cdot 83\end{array}$ & $10 \cdot 45$ & 0.05 \\
\hline
\end{tabular}

provide valuable information about the marker genotype and linkage phase between markers in their parents, many of whom were unavailable for study.

\section{Results}

We have analysed nine di- and tetranucleotide repeat polymorphic markers spanning the $29 \mathrm{cM}$ region of chromosome 14q24.3-q32.2, reported by Takiyama et $a l^{14}$ to contain the gene responsible for MJD (fig 1).
Two point lod scores between the MJD locus and each marker for all seven families examined are shown in table 2. The marker D14S68 is not included in the table since it was analysed in family MJD-B1 only, yielding a maximum lod score of 5.03 at a recombination fraction of 0.03 . The cumulative lod scores for each marker was greater than +3 with the exception of D14S55 which was not very informative. D14S256 showed the highest lod score of 11.07 at a recombination fraction of 0.02 . The maximum likelihood estimates of recombination 


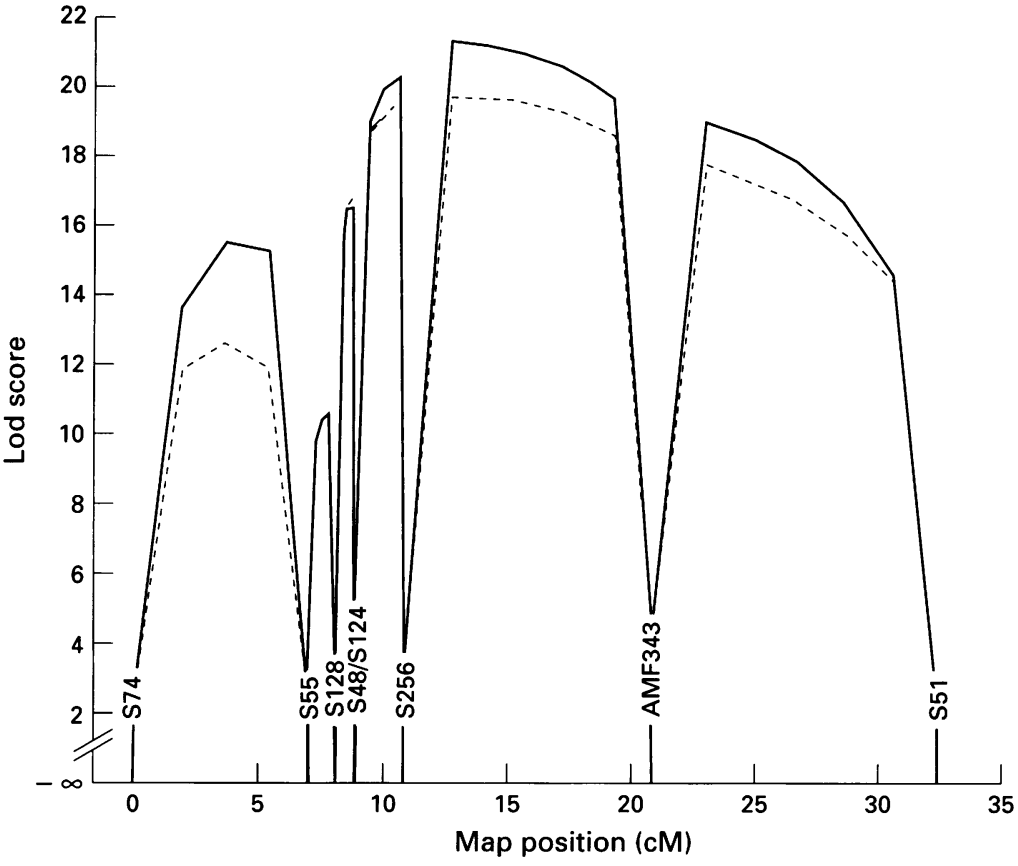

Figure 2 Support for position of the MFD locus with respect to chromosome 14 marker loci. The position of D14S74 was arbitrarily set at 0.00 and the positions of the other loci were fixed according to the genetic map in fig 1 . The solid line indicates the support assuming age dependent penetrance and the dashed line indicates the support assuming incomplete penetrance in at risk persons.

for all other markers were greater than 0.02 . Inspection of the lod scores by family shows that pedigree MJD-B1 is significantly linked (lod greater than 3.0) to D14S48, D14S128, D14S256, AFM343vf1, and D14S51. Lod scores greater than 2.0 were obtained in pedigrees MJD-1 (D14S256) and MJD-2 (D14S74, D14S128, D14S256, and AFM343vf1). The other pedigrees, which had fewer meiotic events, yielded positive lod scores greater than 0.5 with at least one marker. There was no evidence of linkage heterogeneity. Multilocus analysis was carried out using the genetic linkage map shown in fig 1 , to determine the precise location of the MJD gene among the group of chromosome 14q markers analysed. The most likely location for the MJD gene is at a position $2 \mathrm{cM}$ distal to D14S256 and $8 \mathrm{cM}$ proximal to AFM343vf1. However, assuming a one lod unit confidence interval, the MJD gene is not excluded from any of the tested locations between these two flanking markers. The statistical support favouring each order is presented in fig 2 . Odds against the second most likely order (the MJD gene being in the interval immediately proximal to D14S256) are 11 to 1 . The other possible orders are much less likely ranging from 288 to 1 (the MJD gene being in the interval between AFM343vf1 and D14S51) to $5.75 \times 10^{10}$ to 1 (the MJD gene being in the interval between D14S55 and D14S128). The final conclusion and relative position of the MJD gene between the flanking markers was unchanged if zero penetrance in at risk persons was assumed.

Haplotype analysis was carried out on all seven families. The most informative recombinants are shown in fig $3 \mathrm{~A}$ and $\mathrm{B}$ which depict different branches of the largest pedigree, MJD-B1. Fig 3A shows recombination of the chromosome inherited from the affected mother below the marker D14S256 in both subjects 24 and 86 . In fig 3B, subject 538 (whose DNA has not been obtained) appears to have only inherited that portion of the chromosome from her affected parent below the marker D14S68. This can be inferred since her affected daughter, subject 98 , only inherited this portion of the "affected" chromosome from her. In addition, her affected son, subject 540 (whose DNA has also not been obtained), has also inherited this portion of the "affected" chromosome as inferred from his affected daughter, subject 65 . Thus, from these persons, the MJD gene can be localised to that interval below D14S68 and above AFM343vf1, a genetic distance of approximately $11 \mathrm{cM}$. There are, however, a number of persons who inherit this region of chromosome 14 from their affected parent but who are at present asymptomatic. These persons are below the mean age of onset, that is, below 37 years of age, with the exception of subject 26 who is 38 years.

\section{Discussion}

In this paper we show that MJD segregating in seven Portuguese/Azorean families currently living in the United States and one Brazilian family is linked to chromosome 14q24.3-q32, confirming the findings of Takiyama et al. ${ }^{14}$ In their study, they found tight linkage of MJD to the markers D14S55 and D14S48 in five Japanese families. Multiple recombination events were observed between the more centromeric marker D14S53 and the MJD loci and between the more telomeric marker D14S45 and the MJD locus. Thus the gene for MJD was postulated to lie within a $29 \mathrm{cM}$ region flanked by these two markers.

In our families a cumulative two point lod score of +6.25 and +0.74 was obtained with the markers D14S48 and D14S55 respectively with multiple recombination events being observed between both markers and the MJD locus. Our data suggest that the MJD gene is located $8 \mathrm{cM}$ centromeric to AFM343vf1 and $2 \mathrm{cM}$ telomeric to D14S256. From haplotype analysis it can be shown that the MJD locus maps within a $11 \mathrm{cM}$ region flanked by the markers D14S68 and AFM343vf1. At least one recombination event is seen between D14S256 and the MJD locus in family MJD-3B, tentatively placing the MJD locus telomeric to this marker. However, since there are a number of generations of untyped persons in this pedigree, reconstruction of the recombinant haplotypes is problematical at present.

In this study, we did not find linkage disequilibrium with any of the marker loci tested. The evidence for linkage disequilibrium reported by Takiyama et $a^{14}$ is misleading since it appears that they included chromosomes from multiple members (affected and unaffected) from every MJD family. Their sample, which contains only five unrelated MJD chromosomes, is not sufficient for linkage disequilibrium studies. This fact notwithstanding, the multilocus one lod unit confidence interval for the most likely location of MJD in the 

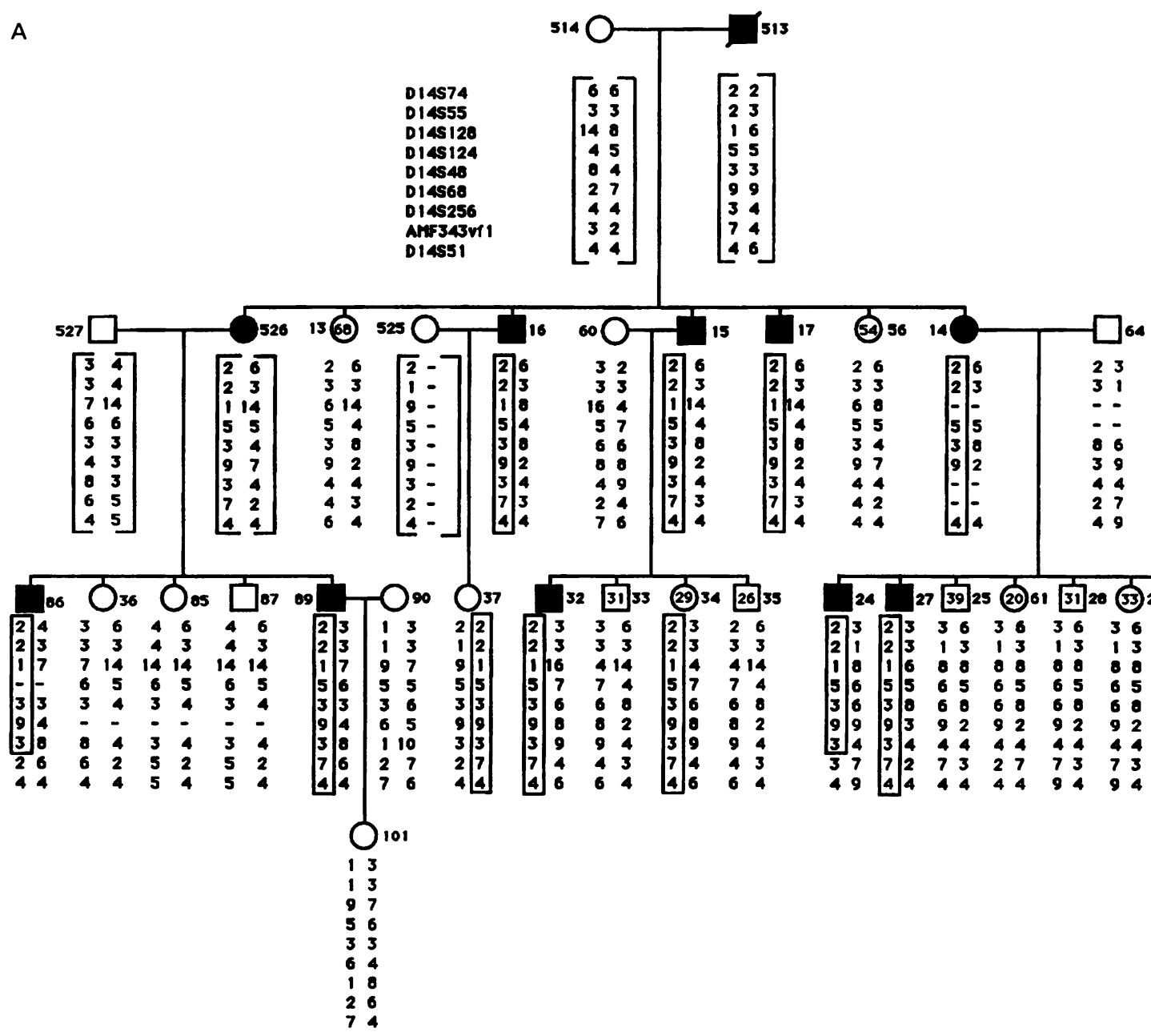

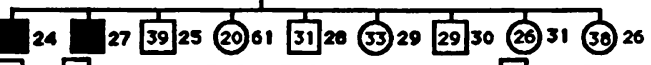

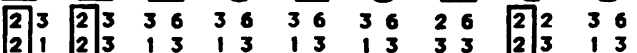

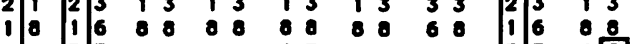

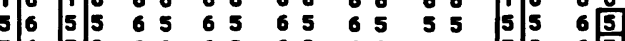

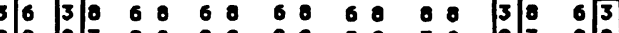

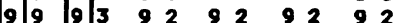

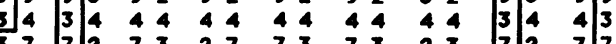

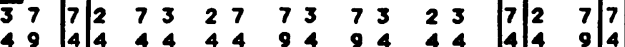

B

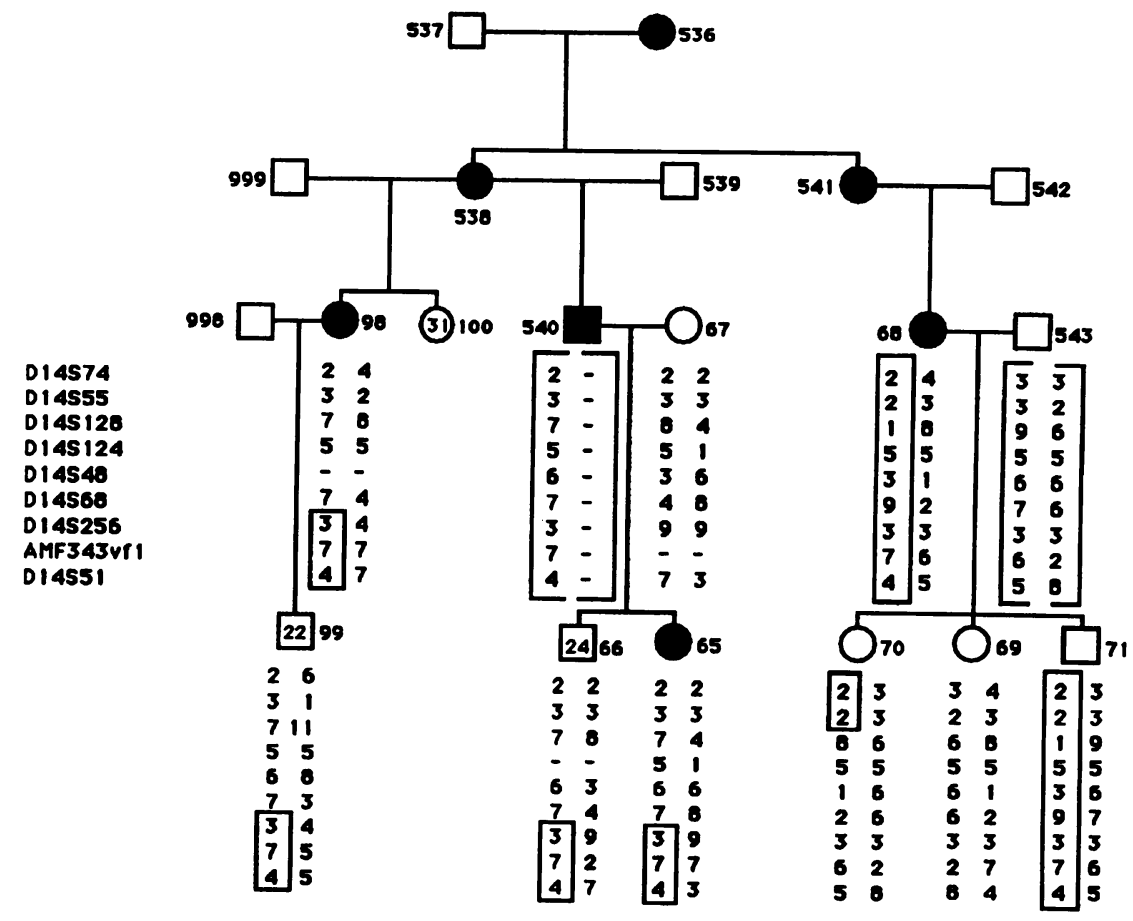

Figure $3 A$ and $B \quad$ Haplotype analysis of part of the MfD-B1 kindred indicating a centromeric and a telomeric marker flanking the interval containing the MFD locus. The haplotype segregating with the disease is surrounded by a box. Bracketed haplotypes have been inferred from offspring. Age of at risk persons (where this information is available) is indicated within the symbol denoting sex. 
Japanese families includes the most likely location for MJD in our group of families.

Recently, another type of autosomal dominant cerebellar ataxia, SCA3, has been linked to the same region of chromosome $14 \mathrm{q}$ as MJD. ${ }^{24}$ The autosomal dominant cerebellar ataxias (ADCA) are clinically and genetically a heterogeneous group and, according to Harding ${ }^{38}$ can be divided into three types: ADCA type 1 can be further subdivided to include MJD, chromosome 6 linked SCA1, chromosome 12 linked SCA2, and SCA3. Linkage of SCA3 to chromosome $14 \mathrm{q}$ was found in two French families using an array of markers spanning the MJD region. ${ }^{24}$ For the markers D14S55 and D14S48, cumulative positive lod scores of 1.73 for a recombination fraction of $0 \cdot 1$ and $1 \cdot 29$ for a recombination fraction of 0.2 were obtained respectively. Thus, in agreement with our data, the SCA3 loci was found not to be tightly linked to either D14S55 or D14S48. From multilocus and haplotype analysis the predisposing SCA3 locus is thought to be located in a $15 \mathrm{cM}$ interval flanked by the markers D14S68 and D14S81. Since MJD and SCA3 have been localised to the same region of chromosome 14 by linkage analysis it is possible that these two disorders are allelic. This hypothesis is further supported by the clinical similarity between the two diseases. From a study by Stevanin $\mathrm{et} \mathrm{al},{ }^{24}$ the mean age of onset and the mean disease duration was shown to be similar between a group of 18 SCA3 patients and $12 \mathrm{MJD}$ patients. In addition, the frequency of the cerebellar signs associated with cerebellar ataxia was not significantly different between the SCA3 patients and the MJD patients with the exception of faciolingual myokymia which was always present in MJD but never in SCA3, and dystonia which was significantly more frequent in MJD compared to SCA3 $(p<0.05)$. However, the clinical symptoms of SCA3 more closely resemble those of SCA $1,{ }^{24}$ the locus of which is known to be on chromosome $6,{ }^{39}$ suggesting that clinical similarity is not necessarily indicative of genetic homogeneity.

A third autosomal dominant neurodegenerative disease, dentatorubropallidoluysian atrophy (DRPLA) has recently been reported to be linked to chromosome $14 \mathrm{q} 24.3$-qter. ${ }^{40}$ However, two independent reports have recently identified an expanded unstable CAG repeat on chromosome $12 p$ in DRPLA patients from Japan, ${ }^{4142}$ a finding which has recently been confirmed in a British DRPLA kindred. ${ }^{43}$ Thus, it is possible that there are two genes responsible for DRPLA located on different chromosomes, although it is more probable that the chromosome 14 linked DRPLA is in fact MJD.

In conclusion, we have shown linkage of MJD to chromosome $14 \mathrm{q}$ in six American families of Portuguese/Azorean descent and in one Brazilian family indicating that MJD segregating in these families is the same as MJD described in Japan. In addition we have narrowed the region of chromosome $14 \mathrm{q}$ containing the MJD gene locus from $29 \mathrm{cM}$ to $11 \mathrm{cM}$, an interval which maps within the re- gion of chromosome $14 \mathrm{q}$ containing the SCA3 locus.

We would like to thank the families for their willingness to participate in this study and Drs B White and J Holden for assistance with lymphoblastoid transformation of cell lines from several American kindreds. We would also like to thank Dr S Marc for information regarding the marker AFM $343 \mathrm{vfl} 1$. Elspeth $C$ Twist is the holder of a Unisource Canada/Alzheimer Society of Canada/MRC fellowship award, Lindsay A Farrer was supof Canada/MRC fellowship award, Lindsay A Farrer was sup-
ported by a fellowship from the Sloan Foundation, and Guy A
Rouleau is supported by the Medical Research Council of Rouleau is supported by the Medical Research Council of
Canada and the Fonds de Recherches en Sante du Quebec and the National Institute of Health.

1 McKusick VA. Mendelian inheritance in man. Catalogs of autosomal dominant, autosomal recessive and $X$-linked phenotypes. 9th ed. Baltimore: The Johns Hopkins University Press, 1990:117.

2 Woods BT, Schaumburg HH. Nigrospinodendal degeneration with nuclear ophthalmoplegia. A unique and partially treatable clinicopathological entity. $\mathcal{f}$ Neurol Sci 1972;17:149-66.

3 Romanul FCA, Fowler HL, Radvany J, Feldman RG, Feingold $M$. Azorean disease of the nervous system. N Engl f Med 1977;296:1501-8.

4 Rosenberg RN, Nyhan WL, Coutinho P, Bay C. Joseph disease: an autosomal dominant neurological disease in the Portuguese of the United States and the Azores Islands. the Portuguese of the Unitel 1978;21:33-57.

5 Coutinho P, Sequeiros J. Aspects clinique et pathologique de la maladie de Machado-Joseph. F Genet Hum 1981;29: de la mala.

6 Sachdev HS, Forno LS, Kane CA. Joseph disease: a multisystem degenerative disorder of the nervous system. Neurology 1982;32:192-5.

7 Sakai T, Ohta M, Ishino H. Joseph disease in a nonPortuguese family. Neurology 1983;33:74-80.

8 Rosenberg RN, Hyhan WL, Bay C, Shore C. Autosomal dominant striatonigral-degeneration. Neurology 1976;26: 703-14.

9 Barbeau A, Roy M, Cunha L, et al. The natural history of Machado-Joseph disease. An analysis of 138 personally examined cases. Can $\mathcal{F}$ Neurl Sci 1984;11:510-25. 10 Rosenberg $\mathrm{RN}$. Dominant ataxias. In: General neurology
and psychiatric disorders. New York: Raven Press, 1983: 195-213.

11 Sequeiros J, Coutinho P. Genetic aspects of Machado Joseph disease. Broteria Genet 1981;77:137-47.

12 Nakano KK, Dawson DM, Spence A. Machado disease: a hereditary ataxia in Portuguese emigrants to Massachusetts. Neurology 1972;22:49-55.

13 Yuasa T, Ohama E, Harayama H, et al. Joseph's disease: clinical and pathological studies in a Japanese family. Ann Neurol 1986;19:152-7.

14 Takiyama Y, Nishizawa $M$, Tanaka $\mathrm{H}$, et al. The gene for Machado-Joseph disease is mapped to human chromosome 14q. Nature Genet 1993;4:300-3.

15 Kitamura J, Kubuki Y, Tsuruta K, Kurihara T, Matsukura S. A new family with Joseph disease in Japan. Homovanilic S. A new family with Joseph disease in Japan. Homovanilic acid magnetic resonance

16 Jain S, Maheshwari MC. Eight families with Joseph's disease in India. Neurology 1990;40:128-31.

7 Bharucha NE, Bharucha EP, Bhabha SK. Machado-JosephAzorean disease in India. Arch Neurol 1986;43:142-4.

18 Burt T, Blumbergs P, Currie B. A dominant hereditary ataxia resembling Machado-Joseph disease in Arnhem Land, Australia. Neurology 1993;43:1750-2.

19 Healton EB, Brust JCM, Kerr DL, Resor S, Penn A. Familial cerebellar ataxia, dystonia, and abnormal eye movements in a non-Portuguese family. Neurology 1979;29:559-60.

20 Cooper JA, Nakada T, Knight R, Friedland RP. Autosomal dominant motor system degeneration in a Black family. Ann Neurol 1983;14:585-7.

21 Livingston IR, Sequeiros J. Machado-Joseph disease in an American-Italian family. $\mathcal{F}$ Neurogenet $1984 ; 1: 185-8$.

22 Suite NDA, Sequeiros J, McKhann GM. Machado-Joseph disease in a Sicilian-American family. $\mathcal{F}$ Neurogenet 1986; 3:77-182.

23 Sequeiros J. In: Lechtenberg R, ed. Handbook of cerebellar disease. New York: Marcel Dekker, 1993:345-51.

24 Stevanin G, Le Guern E, Ravisé N, et al. A third locus for autosomal dominant cerebellar ataxia type I maps to chromol $14 q 24$ 3-qter: evidence for the existence of a fourth locus. Am f Hum Genet 1994;54:11-20.

25 Myers S, MacLeod PM, Forse RA, Forster-Gibson CJ, Simpson NE. Machado-Joseph disease: linkage analysis between the loci for the disease and 18 protein markers. Cytogenet Cell Genet 1986;43:226-8.

26 Carson WJ, Radvany J, Farrer LA, et al. The MachadoJoseph dis, Radvany J, Farrer LA, et al. The MachadoJoseph disease locus is different from the spino.

27 Radvany J, Camargo CHP, Costa ZM, Fonseca NC, NaRadvany J, Camargo CHP, Costa ZM, Fonseca NC, Nascimento ED. Machado-Joseph disease of Azorean ancestry in Brazil:

28 Rouleau GA, Wertelecki W, Haines JL, et al. Genetic linkage of a bilateral acoustic neurofibromatosis to a DNA marker of a bilateral acoustic neurofibromatosis to a

29 Twist EC, Farrer LA, MacLeod PM, et al. Machado Joseph disease is not an allele of the spinocerebellar ataxia 2 locus disease is not an allele of the spinocere
(SCA2). Hum Genet 1994;93:335-8. 
$30 \mathrm{Ott} \mathrm{J}$. Estimation of the recombination fraction in human pedigrees: efficient computation of the likelihood for human linkage studies. Am $\mathcal{F}$ Hum Genet 1974;26:588-97. 31 Hodge SE, Morton LA, Tideman S, Kidd KK, Spence MA. Age-of onset correction available for linkage analysis (LIPED). Am f Hum Genet 1979;31:761-2.

32 Gyapay G, Morisette J, Vignal A, et al. The 1993-94 Généthon human linkage map. Nature Genet 1994;7:246-339.

33 Gerken SC, Matsunami N, Lawrence E, et al. Personal communication to genome database, 1993; GDB Id: G0043-794.

34 Lathrop GM, Lalouel J-M, Julier C, Ott J. Strategies for multilocus linkage analysis in humans. Proc Natl Acad $S_{C i}$ USA 1984;81:3433-6.

35 Braverman MS. An algorithm to improve the computational efficiency of genetic linkage analysis. Comp Biomed Res 1985;18:24-36.

36 Ott J. A simple scheme for the analysis of HLA linkage in pedigrees. Ann Hum Genet 1978;42:255-7.

37 Bowcock AM, Farrer LA, Kavalli-Sforza LL, et al. Mapping the Wilson disease locus in a cluster of linked polymorphic markers on chromosome 13. Am f Hum Genet 1987;41: $27-35$

38 Harding AE. Clinical features and classification of inherited ataxias. In: Harding AE, Deufel T, eds. Advances in neurology. Vol 61. Inherited ataxias. New York: Raven Press, 1993:1-14.

39 Yakura H, Wakisaka A, Fujimoto S, Itakura K. Hereditary ataxia and HLA genotypes. N Engl 7 Med 1974;29:154-5

40 Cancel G, Durr A, Stevanin G, et al. Is DRPLA also linked to $14 \mathrm{q}$ ? Nature Genet $1994 ; 6: 8$.

41 Koide $\mathrm{R}$, Ikeuchi $\mathrm{T}$, Onodera $\mathrm{O}$, et al. Unstable expansion of CAG repeat in hereditary dentatorubral-pallidoluysian atrophy (DRPLA). Nature Genet 1994;6:9-13.

42 Nagafuchi S, Yanagisawa $\mathrm{H}$, Sato $\mathrm{K}$, et al. Dentatorubral and pallidoluysian atrophy expansion of an unstable CAG trinucleotide on chromosome 12p. Nature Genet 1994;6: 14-18.

43 Warner TT, Williams L, Harding AE. DRPLA in Europe. Nature Genet 1994;6:225. 